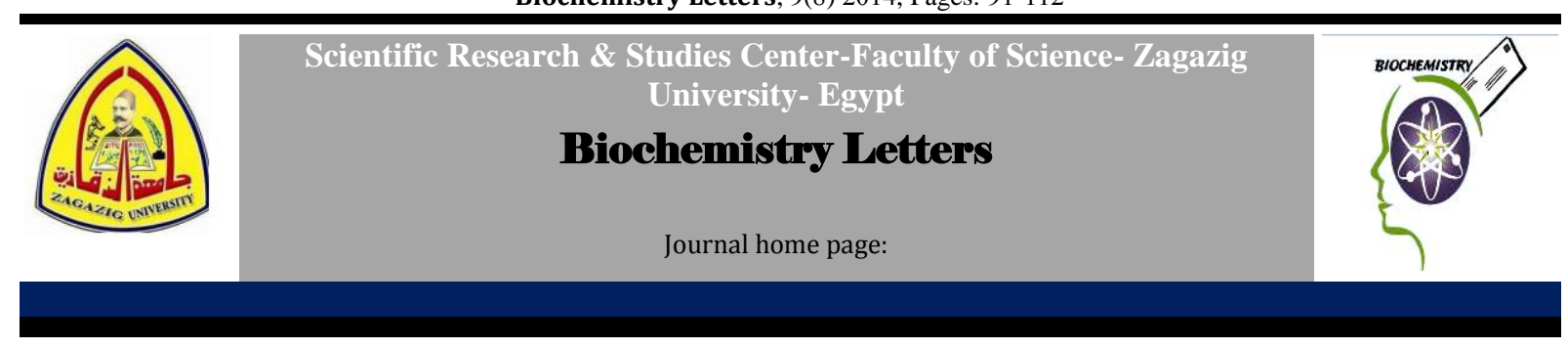

\title{
Role of Irradiated Ehrlich Carcinoma cells and IFNa-2b immunomodulator in Regression of Ehrlich carcinoma in Mice
}

\author{
Neamat HA Osman ${ }^{1}$, Faten M Zahran ${ }^{2}$ and Rokaia E Maarouf ${ }^{1}$ \\ ${ }^{1}$ Egyptian Atomic Energy Authority, National Center for Radiation research and Technology, Radiation Biology Department \\ ${ }^{2}$ Zagazig University - Faculty of Science-Chemistry Department
}

\begin{tabular}{l}
\hline A R T I C L E I N F O \\
\hline Keywords: \\
Irradiated Ehrlich carcinoma cells \\
(vaccine), Ehrlich carcinoma, IFNo- \\
$2 b$
\end{tabular}

$2 b$

Keywords:

Cancer immunotherapy relies on the ability of the immune system to identify and destroy tumor cells and to elicit a long-lasting memory of this interaction. Under ordinary circumstances, however, the ability of tumor cells to trigger an effective immune response is limited [1]. Vaccines have been exceptionally effective against many diseases. In recent years, vaccination has been considered for other diseases, including cancer. Cancer vaccines can be categorized as preventive

\begin{abstract}
A B S T R A C T
Background: Immunotherapy is one of the most promising approaches of cancer treatment. Objective: The present study was designed to examine the role of irradiated Ehrlich carcinoma cells (vaccine) and IFN $\alpha-2 b$ as an immunomodulator in tumor regression. Ehrlich ascites carcinoma cells and 5 groups of female activity were identified in Ehrlich carcinoma from different vaccinated mice. Tumor size monitoring, TNF- $\alpha$ and CEA levels were evaluated. Oxidative stress and antioxidant markers, re examined. Results: The results obtained revealed significant inhibition in tumor size in female mice treated with vaccine or IFN $\alpha-2 b$ either alone or combined. Cas-3 enzymes activities were significantly elevated in different immunized mice Great alterations in oxidative stress, antioxidant markers and apoptotic observations in tumor tissue were recognized after immunizations of mice bearing EC with vaccine and IFN $\alpha-2 b$ action of irradiated Ehrlich carcinoma cells (vaccine) and immunomodulator IFN $\alpha-2 b$ in tumor regression could be postulated.
\end{abstract}


burden of cancer. Treatment or therapeutic vaccines are administered to cancer patients and are designed to strengthen the body's natural defenses against cancers that have already developed [3].

Vaccines used to treat cancers take advantage of the fact that certain molecules on the surface of cancer cells are either unique or more abundant than those found on normal or non-cancerous cells. These molecules, either proteins or carbohydrates, act as antigens, meaning that they can stimulate the immune system to make a specific immune response. Researchers hope that when a vaccine containing cancer-specific antigens is injected into a patient, these antigens will stimulate the immune system to attack cancer cells without harming normal cells [4].

IFNs are a family of natural glycoproteins and regulatory cytokines with pleiotropic cellular functions, such as immunomodulatory and antitumor activity [5].

IFN- $\alpha$ was the main cytokine induced in the innate immune response directed against viral infection [6]. IFN- $\alpha$ has immunomodulatory properties $[7,8]$ and have at least 14 subtypes [9 and 10]. IFN- $\alpha$ is rapidly induced with a high expression level and secreted into the blood circulation in response to viral infection in many types of cells, and then binds to a specific cell surface receptor and triggers intracellular reactions that lead to the transcriptional induction of IFN-stimulated genes (ISGs) [11]. Marshall et al [12] reported that the therapeutic effects of IFN- $\alpha$ on tumor cells were based on Sp1-and/or Sp3-mediated inhibition of VEGF transcription both in vivo and in vitro [5]. The present work was designed to study the antitumor immunity of irradiated tumor cells (vaccine) and/or Interferon alpha- $2 b$ (IFN- $\alpha-2 B$ ) in experimental murine tumor model.

\section{MATERIALS AND METHODS Gamma irradiation:}

The irradiation process was performed using Canadian Ceasium Gamma cell achieved by Egypt's National Center for Radiation Research and Technology (NCRRT), Cairo. The Canadian Ceasium Gamma source is ${ }^{137} \mathrm{Cs}$ irradiation source, model GC 40, manufactured by Nordion Company. The unit provides a mean for uniform Gamma irradiation of biological samples while providing complete protection for operating person. Tumor cell vaccine prepared by exposure of Ehrlich tumor cells to $8 \mathrm{KGy}$ of $\gamma$-radiation.

\section{Interferon alpha-2b (IFN- $\alpha-2 B)$}

IFN- $\alpha-2 B$ was produced by Schering Plough brinny, Innishannon, Country Cork, Ireland wholly owned subsidiary of Schering-Plough Corporation/ U.S.A., and kindly provided by multi-pharma company, Egypt.

Mice were subcutaneously injected with $10.000 \mathrm{IU}$ of IFN- $\alpha-2 \mathrm{~B} 3$ times/ week for 4 weeks [13].

\section{Vaccine preparation:}

Vaccine prepared from tumor cell:

1. Ehrlich ascite carcinoma (EAC) cells were aspirated from the peritoneal cavity of EAC-bearing mice.

2. Cell viability (cells suspension 1:5 (v: v) in $0.4 \%$ trypan blue) was measured by using hemocytometer.

3. The count of cells was adjusted to $2.5 \times 10^{5} / \mathrm{mm}^{3}$.

4. EAC tumor cells were irradiated with $8 \mathrm{KGy} \gamma$-radiation. 
5. EAC cells were lysed according to method of Scchnurr et al [14] with modification.

6. Cells were incubated with $0.01 \%$ EDTA solution for $10 \mathrm{~min}$.

7. The cells were washed twice in PBS, and resuspended at a density of $5 \times 10^{6} / \mathrm{ml}$ in serum-free medium $(0.8 \mathrm{ml} \mathrm{Na} 2 \mathrm{HCo} 3$ and $1 \mathrm{ml}$ of streptomycin-penicillin antibiotics in $100 \mathrm{ml}$ of RPMI 1640 media).

8. The cell suspensions were frozen at $80^{\circ} \mathrm{C}$ and disrupted by four freeze-thaw cycles.

9. For the removal of crude debris, the vaccine was centrifuged for $10 \mathrm{~min}$ at 300Xg.

10 . The mice were injected weekly by 0.2 $\mu l$ of cell vaccine (supernatant) in the right thigh for three successive weeks.

\section{B- Vaccination protocol:}

i. Mice were immunized intramuscularly (i.m) by tumor cell vaccine weekly for 3 weeks in the right thigh of mice.

ii. After two weeks from last immunization, all mice were challenged with normal viable EAC at count of $2.5 \times 10^{6} /$ mouse in the opposite left thigh.

iii. The growth rates of solid tumor in all experimental groups were measured by Caliper. The tumor size measurement in all groups was started at the beginning of pulp appearance in control mice until the volume of tumor reach $1 \mathrm{~cm} 3$ in control group.

iv. The size of solid tumor $\left(\mathrm{mm}^{3}\right)$ was measured according to the following equation according to Papadopoulos et al [15]:

$4 / 3 \pi(\mathrm{A} / 2)^{2} \mathrm{x}(\mathrm{B} / 2)=0.52 \mathrm{~A}^{2} \mathrm{~B}$

$\mathrm{A}$ : minor tumor axis and $\mathrm{B}$ : major tumor axis

\section{2-Experimental design:}

Mice were allowed 10 days for adaptation. 50 mice were randomly distributed into 5 equal groups, 10 mice for each. The different treatments of the present study were done throughout seven weeks.

The animal groups were recognized as follows:

G1: Normal control group. 10 normal mice did not receive any treatment.

G2: Positive control group. 10 mice were intramuscularly injected with $0.2 \mathrm{ml}$ of $2.5 \times 10^{6} / \mathrm{ml} / \mathrm{mouse}$ viable Ehrlich tumor cells in the left thigh.

G3: Vaccinated group. 10 mice were intramuscularly injected with $0.2 \mathrm{ml}$ of irradiated tumor cell (vaccine) in the right thigh one time / week for 3 successive weeks. After 14 days from the last injection; immunized mice were challenged with $0.2 \mathrm{ml}$ of $2.5 \times 10^{5} \mathrm{ml} /$ mouse viable Ehrlich ascite carcinoma cells in the left thigh.

G4: IFN $\alpha-2 b$ immunized mice group. 10 mice were subcutaneously injected with $10.000 \mathrm{IU} /$ mouse three times / week for 4 weeks of immunomodulator (INF $\alpha$-2b). In this group, mice were challenged with viable $0.2 \mathrm{ml}$ of $2.5 \times 10^{6} \mathrm{EC}$ cells /mouse after two weeks of INF $\alpha-2 b$ injection.

G5: Vaccinated IFN $\alpha-2 b$ immunized mice group.10 mice were intramuscularly injected with $0.2 \mathrm{ml} /$ mouse of tumor cell vaccine in the right thigh weekly for 3 successive weeks. After the last immunization mice were subcutaneously injected with $10.000 \mathrm{IU} /$ mouse of IFNa$2 \mathrm{~b}$ three times/ week for 4 weeks. After 2 weeks of IFN $\alpha-2 b$ injection, mice were challenged with $0.2 \mathrm{ml}$ of $2.5 \times 10^{6}$ $/ \mathrm{ml} /$ mouse viable Ehrlich carcinoma cells.

\section{Sample preparation:}

After 2 weeks from Ehrlich challenge, mice were anaesthetized using diethyl ether and sacrificed. Blood and tumor 
tissue from mice of each group were collected and used for the proposed studies.

\section{Preparation of serum:}

Mice were sacrificed and the blood was collected from heart puncher using disposable plastic syringes and drained in heparinized tube and left for coagulation. The blood was centrifuged and the upper layer (serum) was taken. TNF alpha and CEA were measured in serum of each group.

\section{Tissue samples:}

The EC tumor tissue of experimental mice were dissected out, washed and divided into two parts, one part was kept in $10 \%$ formalin for histopathological studies, apoptosis detection and the other part was prepared in ice-cold saline $(0.9 \%)$ using a potter- Elvehjem homogenizer to give a $10 \%$ homogenates which were used for determination of biochemical parameters.

\section{Biochemical analysis}

In serum, the levels of tumor necrosis factor-alpha were assayed by the standard sandwich enzyme-linked immune-sorbent (ELISA) assay technique using ELISA kit (K0331186, KOMABIOTECH, Seoul, Korea) following the manufacturer's instructions, carcinoembryonic antigen (CEA) was determined according to rat CEA ELISA Kit and Caspase-3 activities were determined using a modified procedure [16,17]. In Ehrlich carcinoma tumor tissue lipid peroxidation was measured colorimetrically as described by Yoshioka et al [18], glutathione was measured colorimetrically according to the method of [19], The activity of GSH-Px is determined by using the method of Gross et al [20] superoxide dismutase activity is measured according to the method of [21] and DNA fragmentation was performed by using agarose gel electrophoresis according to Sellins and Cohen [22] with modification.

\section{Histopathological Examination:}

Following mice sacrificing tumor tissues were rapidly dissected and excised, rinsed in saline solution and cut into suitable pieces, then fixed in neutral buffered formalin $(10 \%)$ for 24 hours, following fixation, the specimens were dehydrated in ascending series of alcohol, then tissue specimens were cleared in xylene and embedded in paraffin at $60{ }^{\circ} \mathrm{C}$. Section of 5 microns thickness was cut by slidge microtome. The obtained tissue sections were collected on the glass slides and stained by haematoxylin and eosin stain for histopathological examination by the light microscope [23]. Another tissue sections (2-4 $\mu \mathrm{m}$ thick) were cut from paraffin embedded blocks by microtome and mounted from warm water $\left(40^{\circ} \mathrm{C}\right)$ onto charged adhesive slides. By using a mixture of $100 \mu \mathrm{g} / \mathrm{ml}$ acridine orange and $100 \mu \mathrm{g} / \mathrm{ml}$ ethidium bromide prepared in PBS, the apoptosis and necrosis staining were analyzed [24,25]. The tissue uptake of the stain was monitored under a fluorescence microscope.

\section{RESULTS}

1- The Effect of Tumor Cell Vaccine and/or IFN- $\alpha$-2B on Ehrlich Carcinoma. A- Ehrlich Carcinoma Tumor Size Monitoring:

The size of solid Ehrlich carcinoma (EC) in the left thigh of mice was measured three times along 14 days starting from EC tumor cells inoculation and beginning of tumor formation in control EC bearing mice. The delay and percent of inhibition in tumor size in mice vaccinated with tumor cell vaccine and treated with interferon alpha-2b (IFN- $\alpha-2 b)$ either alone or combined comparing with +ve control mice is represented in Fig (1). 
From Fig.(1), it is clear that the inoculation of 2.5 million of EC cells in $2 \mathrm{ml}$ physiological saline in the left thigh of healthy normal mice produced a solid tumor with a mean size of $225.96 \mathrm{~mm}^{3}$ on the $8^{\text {th }}$ day after tumor inoculation (ATI). EC tumor size exceeds $425.57 \mathrm{~mm}^{3}$ on the $11^{\text {th }}$ day ATI. The increase of EC size proceeds by days reaching $525.37 \mathrm{~mm}^{3}$ on the $13^{\text {th }}$ days ATI.

The data obtained revealed a significant inhibition in tumor size through the observation period in groups of experimental animals treated with tumor cell vaccine and IFN- $\alpha-2 b$ either alone or combined. The mice treated with irradiated tumor cell vaccine exhibited percent of inhibition $61.99 \%$ on the $13^{\text {th }}$ days ATI, while the mice treated with IFN- $\alpha-2 b$ showed $73.50 \%$ percent of inhibition on the $13^{\text {th }}$ days ATI. On the other hand, vaccination EC bearing group with irradiated tumor cell vaccine and IFN- $\alpha-2 b$ represent $112.75 \pm 9.88 \mathrm{~mm}^{3}$ tumor size and $78.54 \%$ percent of inhibition on the $13^{\text {th }}$ ATI.

\section{B-Tumor Markers Responses (TNF- $\alpha$ and CEA) Levels:}

Table (1) represents the effect of tumor cell vaccine and/or INF- $\alpha 2-b$ on serum TNF- $\alpha$ and CEA levels of mice bearing EC. The data revealed that female mice bearing EC represents asignificant increase (lane G3) in EC tumor tissue. In groups of experimental animals treated with IFN- $\alpha$ $2 \mathrm{~b}$ immunomodulator eitheralone or combined with tumor cell vaccine recorded no DNA fragmentation (lane G4\&lane

2- The effect of tumor cell vaccine and/or INF- $\alpha 2-b$ on oxidative stress and antioxidant markers of Ehrlich carcinoma tumor tissue in serum TNF- $\alpha$ and CEA levels in compared to normal control group. Meanwhile treatment of experimental animals bearing EC with tumor cell vaccine represents a significant decrease in tumor TNF- $\alpha$ and CEA levels in compared to EC group. On the other hand, treatment of female mice bearing EC with INF- $\alpha 2-b$ predicts a significant decrease in serum TNF- $\alpha$ and CEA level compared to EC group. while the combined treatment of EC bearing group with tumor cell vaccine and INF- $\alpha 2-b$ in $G_{5}$ shows a highly significant decrease in serum $\mathrm{TNF}-\alpha$ level in comparison with EC group

\section{C- Caspase-3 Detection:}

Table (2) represents the effect of tumor cell vaccine, and INF- $\alpha 2-b$ either alone or combined on tumor caspase (Cas-3) activity of mice bearing EC. Meanwhile treatment of experimental animals bearing EC with tumor cell vaccine represents significant increase in tumor Cas-3 activity when compared with their corresponding activity in EC bearing mice. Treatment of female mice bearing EC with INF- $\alpha 2-b$ predicts a significant increase in Cas-3 activity compared to EC group. The combined treatment of EC bearing group with tumor cell vaccine and INF- $\alpha 2-b$ group $\left(\mathrm{G}_{5}\right)$ shows a significant increase in comparison with Ehrlich group $\left(\mathrm{G}_{2}\right)$ group.

\section{D- DNA Fragmentation:}

Fig. (2) represent the effect EC cells transplantation in the left thigh of mice producing significant DNAfragmentation (laneG2). The treatment of female mice bearing EC with tumor cell vaccine induced significant DNA fragmentation Table (3) represents the effect of tumor cell vaccine and/or INF- $\alpha 2-b$ on tumor MDA and NO levels of mice bearing EC. The data revealed that treatment of 
experimental animals bearing EC with tumor cell vaccine represents a significant increase in tumor MDA level and significant decrease in tumor NO level in compared to EC group.

On the other hand, treatment of female mice bearing EC with INF- $\alpha 2-b$ predicts a significant increase in tumor MDA content and a significant decrease in tumor NO level compared to EC group. Meanwhile the combined treatment of EC bearing mice with tumor cell vaccine and INF- $\alpha 2 b$ shows a significant increase and a significant decrease in tumor MDA and NO levels respectively in comparison with $\mathrm{G}_{2}$ group.

The treatment of experimental animals bearing EC with tumor cell vaccine

\section{4 - Histopathological examination of the Ehrlich carcinoma (EC):}

Histopathological examination possessed normal muscle histology (Fig. 3 A) of nonmice bearing Ehrlich carcinoma. Ehrlich carcinoma (EC) tissue section under light microscope showed compact and aggregation of the tumor tissue cells spread within the muscular tissues. EC showed groups of large, round and polygonal cells, with pleomorphic shapes, hyperchromatic nuclei and binucleation. Several degrees of cellular and nuclear pleomorphism were seen (Fig. 3B). However a section in EC of mice immunized by tumor cell vaccine show great regressing of invaded muscular tissue by EC cells (Fig. 3 C). On the other hand, a section in EC of mice vaccinated by immunomodulator IFN $\alpha-2 b$ shows extensive areas of necrotic EC cells contain nuclear debris and other tumor cells contain pyknotic nuclei (Fig. 3 D). Combined vaccination of mice bearing EC by tumor cell and IFN $\alpha-2 b$ represent great represents a significant decrease in tumor GSH content, no significant effect in GPX activity and a slight increase in tumor SOD activity in compared to EC group.

Treatment of female mice bearing EC with INF- $\alpha 2-b$ predicts decrease in tumor GSH content and GPX activity and increase in tumor SOD activity compared to EC group. Meanwhile the combined treatment of EC bearing group with tumor cell vaccine and INF- $\alpha 2-b$ in $G_{5}$ shows a significant decrease in tumor GSH content and GPX activity and non-significant increase in tumor SOD activity in comparison with $\mathrm{G}_{2}$ group.

necrotic areas contain of remnants and some pyknotic nuclei in EC tissue section (Fig. 3E).

\section{5- Apoptotic and necrotic examination of Ehrlich carcinoma (EC):}

Apoptotic and necrotic stained by Acridine orange / propidium iodide stain and examined under a fluorescent microscope. Normal muscle tissue section represents vital tissue regions stained in green colour (Fig. 4 A). Control section of EC represents vital tissue stained in green stain with no zones of necrosis (orange cells) or apoptosis (yellow cells) in addition to the presence of and some vacuolated areas (Fig. 4 B). Treatment of mice bearing EC by tumor cell vaccine showed many necrotic regions had bright orange colour (Fig. 4C). Also, the vaccination of mice bearing EC by IFN $\alpha-2 b$ shows extensive bright orange areas of necrotic EC cells contain nuclear debris (Fig. 4D). The combined vaccination of mice bearing EC by tumor cell and IFN $\alpha$-2b represents great areas showed necrotic regions had late 
bright orange apoptotic cells and necrotic cells had orange color in addition, to the

Cancer may develop when the immune system breaks down or is not functioning adequately. Tumour immunization (vaccination) is a new and important field in cancer prevention and treatment. Cancer immunization studies used different type of vaccines and different modelities. Success is highest when the specific tumour antigen or genome sequence is known [26, 27, 28, and 29]. Cancer vaccines are another form of biological therapy currently under study. Vaccines for infectious diseases, such as measles, mumps, and tetanus, are effective because they expose the body's immune cells to weakened forms of antigens that are present on the surface of the infectious agent. This exposure causes the immune cells to produce more plasma cells, which make antibodies. In the present study different radiation doses levels were first examined to detect the most preferable dose for irradiation of the Ehrlich tumor cells in order to prepare the vaccine. The Ehrlich tumor cells were irradiated with gamma rays at absorbed dose levels of 6 , 8, and $10 \mathrm{kGy}$, Gamma irradiation at dose 8 kGy was used to enhance the immunogenic properties of EAC cells. Whole EAC cell was used as vaccine in our study.

The autologus tumor cell vaccine intended is a therapeutic agent produced by isolating tumor cells from an individual and processing these tumor cells into a vaccine formulation in vitro. The vaccine is then administered to the individual from whom the tumor cells were isolated [30].The vaccine administration at a location distant from the original tumor is with the objective of stimulating a presence of vital green muscle tissue (Fig.4

$\mathrm{E} \& \mathrm{E}+)$.

\section{DISCUSSION}

systemic reactivity against tumor. The reactivity may in turn eradicate or slow the development of tumor cells, either at the primary site, within metastases (if there are any), or both [31].

Haspel et al [32] suggested that irradiation of 107 colon tumor cells at dose level of about 150,000-20,000 rads of gamma radiation rendered the tumor cells sterile and non-tumourigenic. They measured at least $80 \%$ viability in the irradiated colon tumor cells. They used a pharmaceutically acceptable carrier for intradermal injection.

In the present study mice were vaccinated with irradiated Ehrlich tumor cells at dose of $2.5 \times 10^{5}$ cells three successive weeks pre challlange with $2.5 \times 10^{6}$ viable tumor cells. Transplantation of EAC cells in the right thigh of female Swiss albino mice induced the formation of solid tumor which showed marked increase in its volume weight continuously with time till the end of experiment.

The obtained results clearly reflect the efficacy of the prepared tumor irradiated vaccine in inhibition of tumor growth to a significant extent. The results are going on with the aimed objective of the study. Tumor has larger repertoires of tumorassociated antigens (TAAs), which can lessen the possibility of tumor escape and increase the probability of CTL crosspriming with antitumor activity [33] and it could induces specific cytotoxic $T$ lymphocytes responses and non-specific immunity both of which could contribute to the tumor inhibition [34]. Obviously, the irradiation could increase the expression of these factors, subsequently 
increased the immunogenicity tumor cells. In this respect, it was claimed that the cancer cell irradiation at different levels of gamma rays (10,000 cGy- 18,000 cGy) increased the expression of all surface antigens present on the cells before irradiation, and enhanced the immunogenicity of cellular tumor cells vaccine [35]. Irradiated tumor cells appear to be appropriate simulators of a physiological situation in the tumor bearing organism providing the whole set of tumor antigens and eliminating the need to identify the respective TAA firstly [36]. Biological therapies use the body's immune system, either directly or indirectly, to fight cancer or to lessen the side effects that may be caused by some cancer treatments [37]. Biological response modifiers (BRMs) can alter the interaction between the body's immune defenses and cancer cells to boost, direct, or restore the body's ability to fight the disease. BRMs include interferons, interleukins, colony-stimulating factors, monoclonal antibodies, and vaccines [37]. Interferons are types of cytokines that occur naturally in the body. They were the first cytokines produced in the laboratory for use as BRMs.

The experimental data revealed that the + ve control mice develop Ehrlich tumor bulb exceeded $1 \mathrm{~cm}^{3}\left(500 \mathrm{~mm}^{3}\right) 10$ days ATI of viable EAC cells [38]. However, the obtained data revealed that there is significant decrease in mean of tumor size of the three groups (irradiated, tumor cell vaccinated group and tumor cell vaccine irradiated group) compared to mice group inoculated with viable Ehrlich tumor cells

Also, there is significant decrease in mean of tumor size of the interferon groups (IFN- $\alpha-2 b$ injected group and vaccinated $+\mathrm{IFN}-\alpha-2 b$ ) injected group compared to mice group inoculated with viable Ehrlich tumor cells. Lengyel [39] reported that Interferons exert widely overlapping pleiotropic effects including inhibition of cell growth and modulation of certain immune reactions. The biologic activities also include inhibition of cell proliferation, enhancement of the cytotoxic activities of lymphocytes, the expression of cell surface antigens and stimulation of the phagocytic and tumoricidal activities of macrophages. These properties may play an important role in vivo antiviral and antitumor effects of IFNs [40].

Tumor markers are frequently used in the management of cancer patients especially for determination of the extent of the disease and monitorization of response to therapy. Tumor markers are substances usually of peptide nature secreted by tumor cells. These substances are normally absent in serum, since they are not secreted by normal cells or are secreted in very small amounts [41].

Tumor necrosis factor alpha (TNF- $\alpha)$ is a 17 kilodalton cytokine that is synthesized by monocytes/macrophages, natural killer cells/large granular lymphocytes, and $\mathrm{T}$ lymphocytes subsets. it is a cytokine initially described as a tumoricidal protein, has a variety of functions in the inflammatory and immune response [42]. The role of TNFalpha in chronic inflammatory diseases and tumor-promoting effects is well recognized [43, 44, 45], as well as the role in promoting tumor cell survival through the induction of genes encoding NF$\kappa \mathrm{B}$-dependent anti-apoptotic molecules [45].

The experimental data reveals that female mice bearing EC represents a significant increase in serum TNF- $\alpha$ level 
of tumor bearing mice in compared to normal control group.

The elevation in the TNF- $\alpha$ level in EC mice group may be attributed to the increase in the production of ROS by macrophages, which stimulate lipid peroxidation and thought to have an important pathogenic role in tumor damage [46] .

On the other hand, treatment of experimental animals bearing EC with irradiated EC cells represents a significant decrease in serum TNF- $\alpha$ level in compared to EC group level. It seems likely that a decrease in tumor markers as TNF- $\alpha$ does not always correlate with the strength of the antitumor effects of the therapy. However, tumor markers decrease in accordance with the regression of the cancer by chemotherapy in many cases, as previously reported $[47,48]$.

Also, the treatment of female mice bearing EC with INF- $\alpha 2-b$ predicts a significant decrease in serum TNF- $\alpha$ level compared to EC group for the presence of immune system activation and endothelial injury/activation [49].

Also, the combined treatment of EC bearing group with irradiated EC cells and INF- $\alpha 2-b$ show a highly significant decrease in serum TNF- $\alpha$ level in comparison with EC group.

Another cancer-specific marker is CEA, or carcinoembryonic antigen. It is a bloodborne protein, first noted to be produced by tumors of the gastrointestinal system, lung and breast cancer cases. CEA relationship to extent of the disease and possibly its use in monitoring response to therapy is being increasingly appreciated [50, 51, 52, and 53].

The data revealed that female mice bearing EC represents a significant increase in serum CEA level of tumor bearing mice in compared to normal control group. An elevated level of a tumor marker can indicate the presence of cancer [54]. Elevated CEA demonstrated that the metastasis of tumor occurred or the tumor is at an advanced stage [55] indicate a larger tumor burden [56].

Treatment of experimental animals bearing EC with irradiated EC cells revealed a significant reduction in Ehrlich tumor carcinoma CEA level in compared to EC group level. The majority of preclinical data suggests that the induction of cytotoxic $\mathrm{T}$ cells against a tumor-specific antigen can mediate an effective antitumor response and prevent recurrent malignancy $[57,58]$.

Treatment of female mice bearing EC with INF- $\alpha 2-b$ predicts decrease in serum CEA level compared to EC group. Meanwhile the combined treatment of EC bearing group with irradiated EC cells and INF- $\alpha 2-$ b shows a highly significant decrease in serum CEA level in comparison with EC group.

The cell- multiplication-inhibitory effect was directly proportional to the antiviral activity for any given preparations of interferon. also, interferon has shown promise as an anti-cancer agent in clinical trials [59]. Through the inhibition of DNA synthesis of transformed cells or enhances natural killer and antibodydependent cell-mediated cytotoxicity [60]. Caspases (c: cysteine protease mechanism, aspase: ability to cleave after aspartic acid) are aspartate-directed cysteine proteases that play a key role in the initiation and execution of apoptosis, necrosis and inflammation, failure of which may cause tumor development and several autoimmune diseases [61]. Structural details of several caspases (such as Casp-1, 2, 3, 7, 8 and 9) [62]. Once activated, they cleave 
cellular substrates, leading to morphological hallmarks of apoptosis [63, 64].

EC bearing mice showed high increases in the activity of caspase-3, indicating increase in apoptosis. These observations supported by O'Donovan et al [65] the activity of caspase- 3 is increased in tumor cells due to the inactivation of p53 (tumor suppressor protein), which is responsible for protecting cells from tumorigenic alterations [66].

Meanwhile treatment of experimental animals bearing EC with irradiated tumor cell vaccine represents significant increase in tumor caspase-3 levels when compared with their corresponding activity in EC bearing mice. Also, tumor tissue section shows great regressing of invaded muscular tissue by EC cells and necrotic regions. This suggests that vaccine can destroy the existing tumor cells by activating the apoptotic cascade.

These increases caspase-3 activities postulated the enhancement of apoptosis by full competent working of the apoptotic pathways depending on caspase- 3 despite of vaccine variability. The apoptotic pathway is critical to the ability of natural killer cells and cytotoxic T lymphocytes to induce efficient cell death of virally infected or tumor cell through activation of caspases -3 to induce apoptosis [67].

Nagata [68] showed that the DNA ladder nuclease (now known as caspase-activated DNase or CAD) preexists in living cells as an inactive complex with an inhibitor subunit. Activation of CAD occurs by means of caspase-3-mediated cleavage of an inhibitory subunit, resulting in the release and activation of the catalytic subunit [69]. Hence, our results, the increased caspase-3 activity strongly suggest that tumor cell vaccine activates the apoptotic cascade and implements the antitumor activity on the EC cells.

Tumor vaccine has larger repertories of tumor-associated antigens (TAAs), which can lessen the possibility of tumor escape and increase the probability of Cytotoxic T-Lymphocyte (CTL) cross-priming with antitumor activity [33] and it could induces specific CTL responses and non-specific immunity both of which could contribute to the tumor inhibition [34].

Treatment of female mice bearing EC with INF- $\alpha 2-b$ predicts a significant increase in caspase-3 levels compared to EC group. Also, the slide tissue section shows extensive areas of necrotic EC cells contain nuclear debris and other tumor cells contain pyknotic nuclei.

The way by which tumor cell growth is suppressed may be that IFN $-\alpha 2-b$ induces apoptosis in cancer tissue cells [70] through the triggering of programmed cell death the combined treatment of EC bearing group with irradiated Ehrlich carcinoma cells and INF- $\alpha 2-b$ represents a significant increase in comparison with Ehrlich group and represents great areas of necrotic and apoptotic cells.

There are two distinct types of cell death in cell-biology mechanisms; necrosis and apoptosis, which differ in their process and features. For example, DNA fragmentation, a phenomenon that involves regular DNA cleavage into a unit length of 180-200 bp, is a typical feature of apoptotic cells induced only in apoptotic stimulus. While necrosis is caused by mechanical force or trauma, apoptosis is induced by cellular signals and programmed in the cells for control of human homeostasis, such as removal of damaged or unnecessary cells. Because certain steps of apoptotic processes including DNA fragmentation, are 
impaired in many cancer cells, cancer cells proliferate endlessly and threaten multiplication of other normal cells. For these reasons, many researchers have been looking for apoptotic inducers in cancer cells [17].

Treatment of experimental animals with irradiated Ehrlich cell line represents a significant increase in tumor caspase-3 levels by activating the apoptotic cascade and a significant DNA fragmentation in tumor tissue [71]. Groups of experimental animals treated with IFN- $\alpha-2 b$ immunomodulator either alone or combined with tumor cell vaccine recorded no DNA fragmentation. The disappearance of DNA fragments bands in mice bearing tumor samples postulate loss of apoptosis evident by the tumor development. Some types of cancers are characterized by defects in apoptosis leading to immortal clones of cells [72].

Lipid peroxidation, an autocatalytic free radical chain propagating reaction, is known to be associated with pathological conditions of a cell. It is another important event related to cell death and has been reported to cause severe impairment of membrane function through increased membrane permeability and membrane protein oxidation and eventually cell death by damaging the cellular DNA [73].

Treatment of experimental animals bearing EC with irradiated Ehrlich tumor cell represents a significant increase in tumor MDA level and significant decrease in tumor NO level in compared to EC group. The increase in levels of lipid peroxidation level in tumor tissue might be attributed to the deficiency of antioxidant defense mechanisms or probably due to the generation of reactive oxygen species (ROS) and altered redox statuses which are common biochemical aspects in tumor cells. ROS can react with the polyunsaturated fatty acids of lipid membranes and induce lipid peroxidation. Earlier studies observed increased lipid peroxidation and decreased antioxidant levels in the cancer patients [74].

Context with the findings of Romero et al [75], treatment of female mice bearing EC with INF- $\alpha 2-b$ predicts a significant increase in tumor MDA content and a significant decrease in tumor NO level compared to EC group. Also, the same observation was recorded when EC bearing mice treated with irradiated Ehrlich tumor cells either alone or combined with INF- $\alpha 2-b$. The end product of lipid peroxidation, malondialdehyde, due to its high cytotoxicity and inhibitory action on protective enzymes, is suggested to act as on tumor development [76].

Tirkey et al [77] indicated that oxidative stress causes depletion of intracellular GSH, a reducing agent with its sulhydryl group, leading to serious consequences. The decrease could be due to a feedback inhibition or oxidative inactivation of enzyme protein caused by ROS generation, which can in turn impair the antioxidant defense mechanism leading to increased lipid peroxidation [78]. Excessive lipid peroxidation can cause increased glutathione consumption [79]. Our data revealed that treatment of experimental animals bearing EC with irradiated Ehrlich tumor cell represents a significant decrease in tumor GSH content, no significant effect in GPX activity and a slight increase in tumor SOD activity in compared to EC group. The depletion in glutathione level has been reported to enhance the cell death and apoptosis of the tumor cells along with the 
loss of essential sulfhydryl groups that result in an alteration of the calcium homeostasis and eventually loss of cell viability [80].

Treatment of female mice bearing EC with INF- $\alpha 2-b$ either alone or combined irradiated Ehrlich tumor cells predicts decrease in tumor GSH content and GPX activity and increase in tumor SOD activity compared to EC group.

The depletion of glutathione has been reported to enhance cell death and apoptosis of the tumor cells along with the loss of essential sulfhydryl groups that result in an alteration of calcium homeostasis and eventually loss of cell viability [81].

The results corroborate the findings of Skrzydlewska et al [82], who stated increased plasma and tissue MDA level and SOD activity in colorectal cancer patients.

Indeed, the levels of glutathione, GSHPx, have been shown to be significantly altered in malignant cells [83] and in primary cancer tissues [84], suggesting aberrant regulation of redox homeostasis and stress adaptation in cancer cells or

\section{REFERENCES}

1- Siamak, A. $\mathrm{M}$ and Michael, T. L., 2000. Immunomodulation of cancer: potential use of selectively replicating agents. Journal of Clinical Investigation, 105(9): 1173-1176.

2- Giarelli, E. 2007. Cancer vaccines: a new frontier in prevention and treatment. Oncology (Williston Park), 21(11):11-17

3- Lollini P.L., Cavallo F., Nanni P and Forni G., 2006.Vaccines for tumour prevention. Nature Reviews Cancer, 6(3):204-216. could also be due to exhaustion of the glutathione and antioxidant enzymes because of increased peroxidation [85].

From the previous discussed results we postulated the immunization action of irradiated Ehrlich carcinoma cells (vaccine) and immunomodulator IFN $\alpha-2 b$ in tumor regression.

\section{CONCLUSION}

Tumour cell lysate vaccine and/or IFN- $\alpha$ $2 \mathrm{~b}$ exhibited significant antitumor activity reflected by Reduction in tumor size, Inhibition of tumor markers (TNF- $\alpha$ and CEA), increased caspase-3 and DNA fragmentation, Enhanced lipid peroxidation and nitric oxide in tumor tissue, Reduced spleen oxidative stress (MDA, NO), increased antioxidant enzymes (GSH,GPX and SOD) in spleen tissue, apoptosis and necrosis of tumor tissue. The immunization with the cell lysate vaccine act more efficiently as an immunomdulator. IFN- $\alpha$ $2 \mathrm{~b}$ is a good immunomodulator can help in cancer treatment alone or combined with tumor cell lysate vaccine.

4- Douglas, S. K., 2011. Methods of enhancing the immunogenicity of mycobacteria and compositions for the treatment of cancer, tuberculosis, and fibrosing. lung diseases, EP2329007 A1.

5- Wada, H., Nagano, H., Yamamoto, H., Arai, I., Ota, H., Nakamura, M., Damdinsuren, B., Noda, T., Marubashi, S., Miyamoto, A., Takeda, Y., Umeshita, K., Doki, Y., Dono, K., Nakamori, S., Sakon, M and Monden, M., 2007. Combination therapy of interferon-alpha and 5 fluorouracil inhibits tumor angiogenesis in human 
hepatocellular carcinoma cells by regulating vascular endothelial growth factor and angiopoietins. Oncology, Reports, 18:801-809.

6- Fensterl, V and Sen, G.C., 2009. Interferons and viral infections. Biofactors, 35: 14-20.

7- Nakamura, M., Nagano, H., Sakon, M., Yamamoto, T., Ota, H., Wada, H., Damdinsuren, B., Noda, T., Marubashi, S., Miyamoto, A., Takeda, Y., Umeshita, K., Nakamori, S., Dono, $\mathrm{K}$ and Monden, M., 2007. Role of the Fas/FasL pathway in combination therapy with interferon-alpha and fluorouracil against hepatocellular carcinoma in vitro. Journal of Hepatology, 46:77-88.

8- Yamamoto, T., Nagano, H., Sakon, M., Wada, H., Eguchi, H., Kondo, M., Damdinsuren, B., Ota, H., Nakamura, M., Wada, H., Marubashi, S., Miyamoto, A., Dono, K., Umeshita, K., Nakamori, S., Yagita, $\mathrm{H}$ and Monden, M., 2004. Partial contribution of tumor necrosis factor-related apoptosisinducing ligand (TRAIL)/TRAIL receptor pathway to antitumor effects of interferon-alpha/5-fluorouracil against Hepatocellular Carcinoma. Clinical Cancer Research, 10:78847895.

9- Pestka, S and Meager, A., 1997. Interferon standardization and designations. Journal Interferon Cytokine Research, 17(1):S9-S14.

10- Pestka, S., 1997. The human interferonalpha species and hybrid proteins. Seminar Oncology, 24:S9-S17.

11-Kovarik, P., Sauer, I and Schaljo, B. 2007. Molecular mechanisms of the anti-inflammatory functions of interferons. Immunobiology, 212: 895901.
12-Marshall, von Z., Scholz, A., Cramer, T., Schafer, G., Schirner, M., Oberg, K., Wiedenmann, B., Hocker, $M$ and Rosewicz, S., 2003. Effects of interferon alpha on vascular endothelial growth factor gene transcription and tumor angiogenesis. Journal of the National Cancer Institute, 95:437-448.

13- Freund, M., von, Wussow, P., Diedrich, H., Eisert, R., Link, H., Wilke, $\mathrm{H}$ and Buchholz, F., 1989. Recombinant human interferon (IFN) alpha-2b in chronic myelogenous leukaemia: dose dependency of response and frequency of neutralizing anti-interferon antibodies. British Journal of Haematology, 72: 350-356.

14-Scchnurr, M., Galambos, P., Schoz, C.h. Then, F., Dauer, M., Endres, S and Eigler, A., 2001. Tumor cell lysatepulsed human denderitic cells induce a T-cell response against pancreatic carcinoma cells: an in vitro model for the assessment of tumor vaccines. Cancer Research, 61:6445-6450.

15- Papadopoulos, D., Kimler, B.F., Estes, N.C and Durham, F.J., 1989. Growth delay effect of combined interstitial hyperthermia and branchytherapy in a rat solid tumor model. Anticancer Research, 9:45-47.

16- Jaeschke, H., Fisher, M. A., Lawson, J. A., Simmons, C. A., Farhood, A and Jones, D. A., (1998). Activation of caspase 3 (CPP32)-like proteases is essential for TNF- $\alpha$-induced hepatic parenchymal cell apoptosis and neutrophil-mediated necrosis in a murine endotoxin shock model. Journal of Immunology, 160: 3480-3486.

17- kim, Y. M., Kim, T. H., Chung, H. T., Talanian, R. V., Yin, X. $\mathrm{M}$ and Billiar, T. R., 2000. Nitric oxide prevents tumor necrosis factor $\alpha$ - 
induced rat hepatocyte apoptosis by the interruption of mitochondrial apoptotic signaling through S-nitrosylation of caspase-8. Hepatology, 32: 770-778.

18- Yoshioka T., K and Kawada., et al., 1979. lipid peroxidation inmaternal and cord blood and protective mechanism against activated oxygen toxicity in the blood. American Journal of Obstetrics \& Gynecology, 135: 372-376.

19- Beutler, E and O. Duron., et al., 1963. Improved method for the determination of blood glutathione. Journal of Laboratory and Clinical Medicine, 61(5): 882-888.

20-Gross, R. T., R and Bracci., et al., 1967. Hydrogen Peroxide Toxicity and Detoxification in the Erythrocytes of Newborn Infants. Journal of Blood, 29(4): 481 - 493.

21-Minami, M and Yoshikawa, H., 1979. Asimplified assay method of superoxide dismutase activity for clinical use. Clinica Chimica Acta, 92(3): 337-342.

22-Sellins, K. S and Cohen, J. J., 1991. Cytotoxic $\mathrm{T}$ lymphocytes induce different types of DNA damage in target cells of different origin. Journal of Immunology, 147: 795.

23-Banchroft, J.D., Stevens, A and Turner, D.R.,1996. Theory and practice of histological techniques. Fourth Ed. Churchil Livingstone, New York, London, San Francisco, Tokyo.

24- Coligan, J.E., Kruisbeek, A.M., Margulies, D.H., Shevach, E.M and Strober, W., 1995. Current protocols in immunology. In: Coico R, editor. Related isolation procedures and functional assays, vol. 1. John Wiley \& Sons, Inc.3.17.1.

25-Ribble, D., Goldstein, N.B., Norris, D.A and Shellman, Y.G., 2005. A simple technique for quantifying apoptosis in 96-well plates. BMC Biotechnol, 10:5-12.

26- Bodey, B., Bodey B. J. r and Siegel S.E, et al., 2000. Failure of cancer vaccines: the significant limitations of this approach to immunotherapy. Anticancer Research, 20: 2665-2676.

27-Zhu, J., Shi, H and Zhang, H., 2000. Photodynamic therapy of malignancy of skin with a $\mathrm{He}-\mathrm{Ne}$ laser. Chin Journal Lasers, 27: 95-96.

28-Liu, B.Y., Chen, X.H and Gu, Q.L., et al., 2004. Antitumor effects of vaccine consisting of dendritic cells pulsed with tumor RNA from gastric cancer. Gastric Cancer, 10: 630-633.

29- Niu, H., Dong, Z and Dong, F., 2004. Experimental and clinical research of dendritic cell and syngeneic immunotherapy of brain glioma. The Chinese-German Journal of Clinical Oncology, 3:147-1450.

30- Khleif, S., 2005. Tumor immunology and cancer vaccines. Kluwer Acad.Pub.pp.3-5.

31-Hiserodt， J. C., Graf， M. R and Granger, G. A., 2007. Cancer immunotherapy using autologous tumor cells combined with cells expressing a membrane cytokine. United States Patent, 7(264): 820 B2.

32- Haspel, M. V., Pomato, $\mathrm{N}$ and Hanna Jr, M. G., 2009. Sterile immunogenic non-tumorigenic tumor cell compositions and methods. European Patent, EP1567175.

33-Lu, J., Zhang, Q., Liang, C.M., Xia, S.J., Zhong, C.P and Wang D.W., 2008. Antitumor immunity by a denderitic cell vaccine encoding secondary lymphoid chemokine and tumor lysate on marine prostate cancer. 
Asian Journal of Andrology, 10:883889.

34-Dong, B., Sun, L., Wu, X., Zhang, P., Wang, L., Wei, H., Zhou, L., Hu, X., Yu, Y., Hua, S and Wang, L., 2010. Vaccination with TCL plus MHSP65 induces anti-lung cancer immunity in mice. Cancer Immunology, Immunotherapy, 59 (6):899-908.

35- Chiriva-Internati, M., Grizzi, F., Pinkston, J., Morrow, K.J., D’Cunha, N., Frezza, E.E., Muzzio, P.C., Kast, W.M and Cobos, E., 2006. Gammaradiation upregulates $\mathrm{MHC}$ classI/II and ICAM-I molecules in multiple myeloma cell lines and primary tumors. In Vitro Cellular \& Developmental Biology - Animal, 42:89-95.

36- Novakovic, S., Stegel, V., Kopitar, A., Ihan and Novakovic, B.J., (2007): Preventive and therapeutic antitumor effect of tumor vaccine composed of CpG ODN class $\mathrm{C}$ and irradiated tumor cells is triggered through the APCs and activation of CTLs. Vaccine, 25:82418256.

37-Leung, M.Y.K., Liu, C., Koon, J.C.M and Fung, K.P. (2006). Polysaccharide biological response modifiers. Immunology Letters, 105:101-111

38-Kushi, A., Pallavi, A., Anup, K., Rashmi, K and Pravir, K., 2011. Quercetin mediated reduction of angiogenic markers and chaperones in DLA-Induced solid tumours. Asian Pacific journal of cancer prevention, 12: 2829-2835.

39-Lengyel, P., 1982. Biochemistry of interferons and their actions. Annual Reviews of Biochemistry, 51:251-282.

40-Corrnelissen, A., Hoff , j., Maltha, J and Jagtnan, M., 1999. Effects of interferon on proliferation and collagen synthesis of rat palatal wound fibroblasts. Archives of Oral Biology, 44: 541-547.

41-Coskun, A., Ekicibil, A., Ozcelik, B and Kyymaç, K., 2005. Effects of annealing time on themagnetic properties of a Bi1. 7Pb0.29Gd0.01Sr2Ca3Cu4O12+y superconductor prepared by the meltquenching method. Chinese Journal of Physics, 43(2): 372-383.

42- Goeddel, D. V., Aggarwal, B. B., Gray, P. W., Leung, D.W and Nedwin, G. E. et al., 1986. Tumor necrosis factors:gene structure and biological activities. Cold Spring Harbor symposia on quantitative biology,61: 597-609.

43-Lin, W.J and Yeh, W.C, 2005. Implication of Toll-like receptor and tumor necrosis factor alpha signaling in septic shock. Shock, 24(3):206-209.

44- Mocellin, S., Rossi, C.R., Pilati, P and Nitti, D., 2005.Tumor necrosis factor, cancer and anticancer therapy. Cytokine Growth Factor Reviews, 16(1):35-53.

45- Luo, J.L., Maeda, S., Hsu, L.C., Yagita, $\mathrm{H}$ and Karin, M., 2004. Inhibition of NF-kappa B in cancer cells converts inflammation- induced tumor growth mediated by TNF alpha to TRAILmediated tumor regression. Cancer Cell, 6(3):297-305.

46- Abd El-Dayem , S.M., Fouda , F.M., Ali , E.H and Abd El Motelp, B.A., 2012. The antitumor effects of tetrodotoxin and/or doxorubicin on Ehrlich Ascites carcinoma-bearing female mice. Toxicology and Industerial Health, 1:1-14.

47- Bast, R.C., Klug, T.L and Schaetzl, E.R.N. et al., 1984. Monitoring human ovarian carcinoma with a combination of CA125, CA19-9 and 
carcinoembryonic antigen. American Journal of Obstetrics Gynecology, 149:553-559.

48-Horn, Y., Beal, S.L and Walach, N., et al., 1984. Relationship of urinary polyamines to tumor activity and tumor volume in patients. Cancer Research ,44: 4675-4678.

49-Kosar, A., Haznedaroglu, S., Karaaslan, Y., Büyükasik, Y., Haznedaroglu, I. C., Ozath, D., Sayinalp, N., Ozcebe, O., Kirazli, S and Dündar, S., 1999. Effects of interferonalpha2a treatment on serum levels of tumor necrosis factor-alpha, tumor necrosis factor-alpha2 receptor, inter.leukin-2, interleukin-2 receptor, and E-selectin in Behçet's disease. Rheumatology International, 19: 11-19.

50- Koepke, J.A., 1992. Molecular marker test standardization.Cancer, 69 (6): 1578-1581.

51- Takagawa, R., Fujii, S., Ohta, M., Nagano, Y., Kunisaki, $\mathrm{C}$ and Yamagishi, S., et al., 2008.Preoperative serum carcinoembryonic antigen level as a predictive factor of recurrence after curative resection of colorectal cancer. Annals of Surgical Oncology, 15 :3433-3439.

52- Kosmider, S., Stella, D.L., Field ,K., Moore, M., Ananda, S and Oakman, C., et al., 2008. Preoperative investigations for metastatic staging of colon and rectal cancer across multiple centres what is current practice? Colorectal Discussions, 11(6):592-600.

53-Tan, E., Gouvas, N., Nicholls, R.J., Ziprin, P., Xynos, E and Tekkis, P.P., 2008. Diagnostic precision of carcinoembryonic antigen in the detection of recurrence of colorectal cancer. Surgical Oncology, 18(17): 2121-2126.
54- Pamies, R. J and Crawford, D. R., 1996. Tumor markers. Update. The Medical Clinics of North America, 80(1):185-199.

55-Stillwell, A. P., Ho, Y. H and Veitch, C. 2011. Systematic review of prognostic factors related to overall survival in patients with stage IV colorectal cancer and unresectable metastases. World Journal of Surgery, 35, 684-692.

56- Samanci, A., Yi, Q., Fagerberg, J., Strigard, K., Smith, G., Ruden, U., Wahren, B and Mellstedt, H., 1998. Pharmacological administration of granulocyte/macrophage-colonystimulating factor is of significant importance for the induction of a strong humoral and cellular response in patients immunized with recombinant carcinoembryonic antigen. Cancer Immunology and Immunotherapy, 47: 131-142.

57-Gold, P and Freedman, S.O., 1965. Specific carcinoembryonic antigens of the human digestive system. Journal of Experimental Medicine, 122(3): 467481.

58-Zimmermann, W., Weber, B., Ortlieb, B., Rudert, F., Schempp, W., Fiebig, H. H., Shively, J. E., von Kleist, S and Thompson, J. A., 1988.Chromosomal localization of the carcinoembryonic antigen gene family and differential expression in various tumors. Cancer Research, 48: 2550 -2554.

59-Baron, S and Dianzani, F., 1977. The interferon system: a current review to 1978. Texas Reports on Biology \& Medicine, 35: 1-547.

60- Attallah, A.M., Folks, T., Noguchi, P., Noguchi, C. T and Ahmed, A., 1979. Enhanced human natural killer and antibody- dependent cell cytotoxicity 
by incubation with human interferon.

Federation proceedings, p.1279, abstract. 5563.

61- Green, D. R., Ferguson, T., Zitvogel, L and Kroemer, G., 2009. Immunogenic and tolerogenic cell death. Nature Reviews Immunology, 9:353-963.

62- Yan, N and Shi, Y., 2005. Mechanisms of apoptosis through structural biology. Annual Review of Cell and Developmental Biology, 21:35-56.

63-Zhang. L., Yu, J., Park, B. H., Kinzler, K.W and Volgestein, B., 2000. Role of Bax in the apoptotic response to anticancer agents. Science, 290: 989992.

64-Savill, J and Fadok, V., 2000. Corpse clearance defines the meaning of cell death. Nature, 407(6805):784-688.

65- O’Donovan, N., Crown, J., Stunell, H., Hill, A.D.K., McDermott, E., O'Higgins, N and Duffy, M.J., 2003. Caspase 3 in Breast Cancer. Clinical Cancer Research,9: 739:738.

66- Ramnath, V., Rekha, P. S. G., Kuttan, $\mathrm{G}$ and Kuttan, R., 2009. Regulation of Caspase-3 and Bcl-2 Expression in Dalton's Lymphoma Ascites Cells by Abrin. Alternative Medicine, 6(2):223-238.

67-Loeb, S., Roehl, K., Antenor, J., Catalona, W., Suarez, B. K and Nadler, R., 2006. Baseline prostate-specific antigen compared with median prostate-specific antigen for age group as predictor of prostate cancer risk in men younger than 60 years old. Urology, 67: 316-320.

68- Nagata, S and Golstein, P., 1995.The Fas death factor. Science, 267:14491456.

69- Nicholson, D. W., 1995. Identification and inhibition of the ICE/CED-3 protease necessary for mammalian apoptosis. Nature, 376: 37- 43.

70-Caraglia, M., Tagliaferri, P., Budillon, A and Abbruzzese, A., 1999. Posttranslational modifications of eukaryotic initiation factor-5A (eIF5A) as a new target for anti-cancer therapy. Advances in Experimental Medicine and Biology, 472: 187-198.

71- Heibein , J.A., Barry, M., Motyka , B and Bleackley, R.C. 1999. Granzyme $B$ induced loss of mitochondrial inner membrane potential and cytochrome c release are caspase independent. Journal of Immunology, 163: 4683-4693.

72- Ghobrial, I.M., Witzig, T.E and Adjei, A.A., 2005. Targetting apoptosis pathways in cancer therapy. CA Cancer Journal of Clinics, 55: 178-194.

73- Marnett, L.J., 2002. Oxyradicals,lipid peroxidation and DNA damage. Toxicology,27:219-222.

74-Manju, V., Kalaivani-Sailaja, J and Nalini, N., 2002. Circulating lipid peroxidation and antioxidant status in cervical cancer patients: a case-control study. Clinical Biochemestry, 35: 621625.

75-Romero, M. J., Bosch-Morell, F., Romero, B., Rodrigo, J.M., Sera, M.A and Romero, F.J., 1998. Serum Malondialdehyde: Possible use for the clin-ical management of chronic hepatitis C patients. Free Radical Biology and Medicine, 25:993-997.

76- Kang, D.H., 2002. Oxidative stress, DNA damage breast cancer. American Association of Critical-Care Nurses clinical Issues, 13: 540-549.

77- Tirkey, N., Pilkhwl, S., Khad, A and Chopra, K., 2005. Hesperidin, a citrus bioflavonoid, decreases the oxidative stress produced by carbon tetrachloride 
in rat liver and kidney. BMC Pharmacology, 5(2): 1-8.

78- Ohta, Y., Kongo, N., Nishimra, M., Matsura, T., Yamada, K., Kitagawa, A and Kishikaw, T., 2004. Melatonin prevents disruption of hepatic reactive oxygen species metabolism in rats treated with carbon tetrachloride. Journal of Pineal Research, 36(1): 1017.

79- Manda, K and Bhatia, A. L., 2003. Preadministration of beta-carotene protects tissue glutathione and lipid peroxidation status following exposure to radiation. Environmental Biology, 24(4): 369-372.

80- Neal, R. M., 2003. Density modeling and clustering using Dirichlet diffusion trees", in J. M. Bernardo, et al. (editors). Bayesian Statistics, 7: 619629.

81-Meister, A and Anderson, M.E., 1983.Glutathione. Annual Review of Biochemistry, 52:711-760.

82- Skrzydlewska, E., Stankiewicz, A., Sulkowska, M., Sulkowski, S and
Kasacka, I., 2001. Antioxidant status and lipid peroxidation in colorectal cancer. Journal of Toxicology and Environmental Health, 64: 213-222.

83-Oberley T. D., 1997. Antioxidant enzyme levels in cancer. Histology and Histopathology, 12(2): 525-535.

84-Murawaki, Y., suchiya, H.T and Kanbe, T., 2008.Aberrant expression of selenoproteins in the progression of colorectal cancer. Cancer Letters, 259 (2): 218-230.

85- Anbazhagen, $\mathrm{M}$ and Chellappan, P.R., 2009. Activities of antioxidant enzyme and lipid peroxidation in ovarian cancer patients. Academic Journal of Cancer Research, 2(2): 68-72. 
Table (1): The effect of tumor cell vaccine and/or INF- $\alpha$ on serum TNF- $\alpha$ and CEA levels of mice bearing EC.

\begin{tabular}{|c|c|c|c|c|c|}
\hline $\begin{array}{l}\text { Group } \\
\text { Parameters }\end{array}$ & G1 & G2 & G3 & G4 & G5 \\
\hline $\mathbf{T N F}(\mathrm{pg} / \mathrm{ml})$ & $86 \pm 4.95$ & $223 \pm 8.13^{\mathrm{a}}$ & $112 \pm 3.64^{\mathrm{ab}}$ & $120.75 \pm 7.28^{\mathrm{ab}}$ & $92.10 \pm 14.91^{\mathrm{ab}}$ \\
\hline CEA (pg/ml) & $1.76 \pm 0.07$ & $2.77 \pm 0.31^{\mathrm{a}}$ & $2.19 \pm 0.017$ & $2.407 \pm 0.29$ & $1.355 \pm 0.083^{\mathrm{ab}}$ \\
\hline
\end{tabular}

Values are expressed as means of 10 records \pm standard Error $(\mathrm{M} \pm \mathrm{SE})$.

a: significant against $\mathrm{NC}$ at $\mathrm{P}<0.05 \quad$ b: significant against $\mathrm{EC}$ at $\mathrm{P}<0.05$

G1: -ve control, G2: EC, G3: EC of mice treated by tumor cell vaccine, G4: EC of mice treated by IFN $\alpha-2 b$, G5: EC of mice vaccinated by tumor cell vaccine and IFN $\alpha-2 b$

Table (2): The effect of tumor cell vaccine and/or INF- $\alpha 2-b$ on tumor caspase levels $(\mu \mathrm{mol}$ $\mathrm{pNA} / \mathrm{min} / \mathrm{ml}$ ) of mice bearing EC.

\begin{tabular}{|c|c|c|c|c|}
\hline Group & G2 & G3 & G4 & G5 \\
\hline Mean \pm SE & $122.63 \pm 8.19$ & $138 \pm 4.73$ & $182.47 \pm 14.88^{\mathrm{b}}$ & $182.15 \pm 13.11^{\mathrm{b}}$ \\
\hline
\end{tabular}

Legends as in table (2)

Table (3): The effect of tumor cell vaccine and/or INF- $\alpha$ on antioxidants markers of EC tumor.

\begin{tabular}{|c|c|c|c|c|}
\hline Garameter & G2 & G3 & G4 & G5 \\
\hline $\begin{array}{c}\text { MDA (mM/gm tissue } \\
\text { homogenate) }\end{array}$ & $21.66 \pm 1.43$ & $50.22 \pm 1.07^{\mathrm{b}}$ & $30.72 \pm 1.86^{\mathrm{b}}$ & $92.10 \pm 6.09^{\mathrm{b}}$ \\
\hline NO $(\mathrm{M} \mathrm{mole} / \mathrm{L})$ & $45.69 \pm 2.78$ & $38.24 \pm 2.96^{\mathrm{b}}$ & $31.27 \pm 2.28^{\mathrm{b}}$ & $32.67 \pm 1.38^{\mathrm{b}}$ \\
\hline $\begin{array}{c}\text { GSH }(\mathrm{mg} \mathrm{GSH} / 1 \mathrm{gm} \\
\text { tissue })\end{array}$ & $26.95 \pm 0.70$ & $24.06 \pm 0.68^{\mathrm{b}}$ & $25.66 \pm 0.52$ & $22.71 \pm 0.88^{\mathrm{b}}$ \\
\hline $\begin{array}{c}\text { GPX }(\mathrm{mg} / \mathrm{min} / \mathrm{gm} \\
\text { tissue })\end{array}$ & $0.45 \pm 0.01$ & $0.45 \pm 0.00$ & $0.43 \pm 0.01^{\mathrm{b}}$ & $0.11 \pm 0.00^{\mathrm{b}}$ \\
\hline $\begin{array}{c}\text { SOD } \\
(\mu \mathrm{g} \mathrm{SOD} / \mathrm{ml})\end{array}$ & $7.09 \pm 0.25$ & $7.64 \pm 0.55$ & $8.39 \pm 0.19$ & $7.36 \pm 0.61$ \\
\hline
\end{tabular}

Legends as in table (2) 


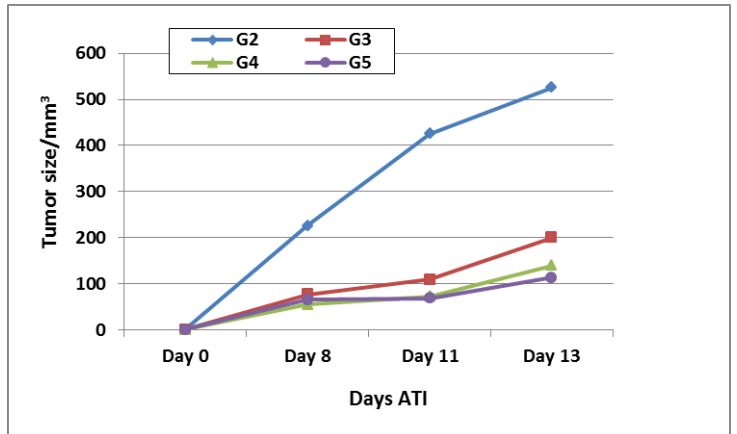

Fig. (1) Effect of irradiated tumor cell vaccine and IFN- $\alpha-2 b$ alone or combined on EC tumor size

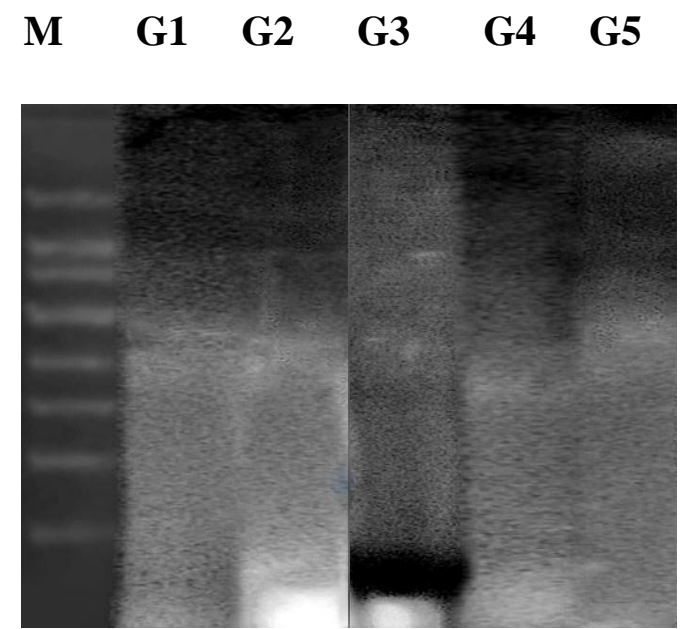

Fig. (2): Effect of tumor cell vaccine and/or IFN- $\alpha 2 b$ on EC DNA fragmentation. Lane G1: -ve control, Lane G2: EC, Lane G3: EC of mice treated by tumor cell vaccine, Lane G4: EC of mice treated by IFN $\alpha-2 b$, Lane G5: EC of mice vaccinated by tumor cell and IFN $\alpha-2 b$ 

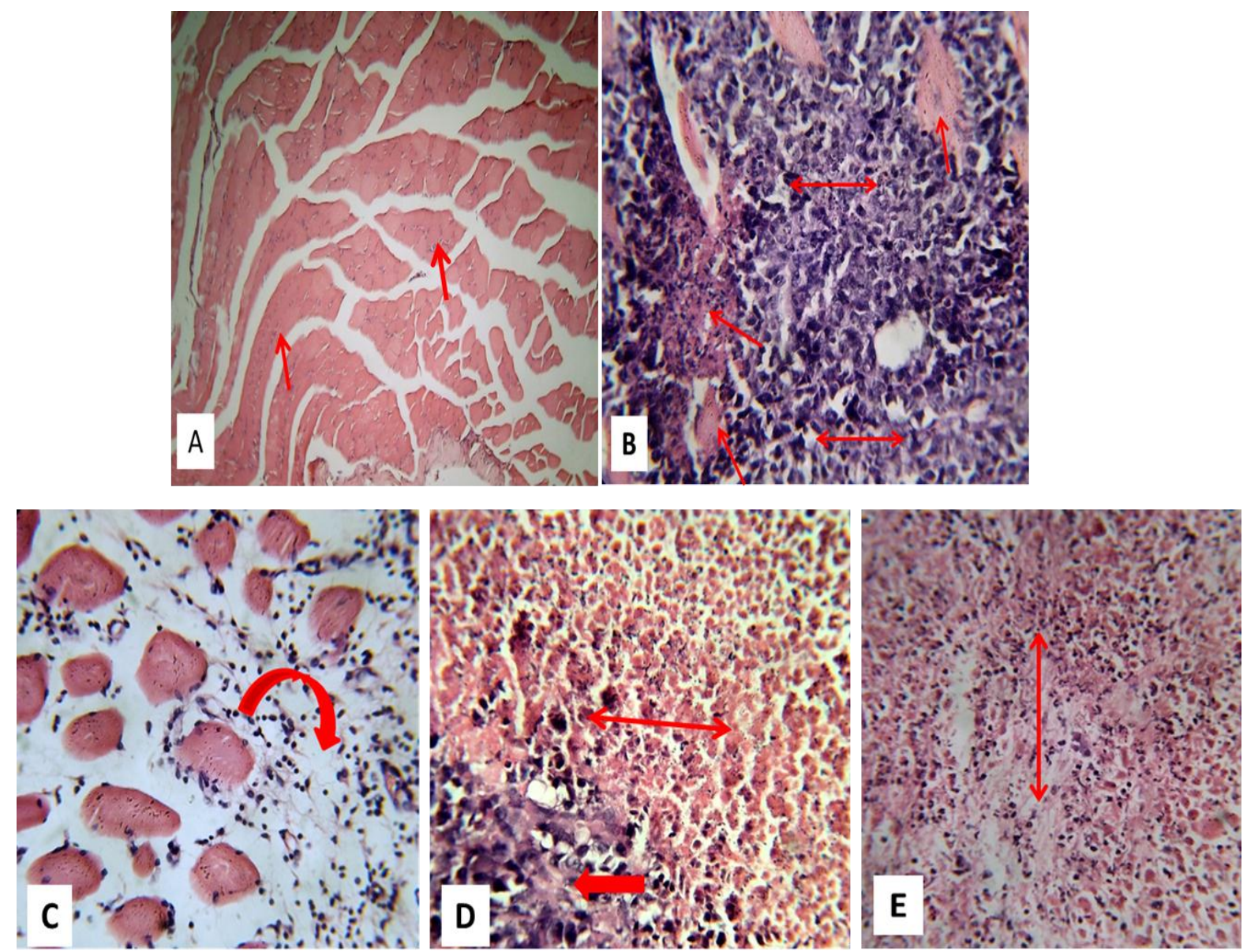

Fig. (3): Photomicrographs in sections of EC. A: Normal control muscle section in Albino mice represents normal muscular fiber $(\uparrow)$. B: Control EC. Note: $(\uparrow)$ EC cells invaded muscular tissue; $(\leftrightarrow)$ tumor cells encircled the muscles cells. C: Sections in EC of mice treated by tumor cell vaccine shows great regressing of invaded muscular tissue by EC cells (curved arrow). D: Sections in EC of mice treated by IFN $\alpha-2 b$ shows extensive areas of necrotic EC cells contain nuclear debris $(\uparrow)$ and other tumor cells contain pyknotic nuclei (red blocked arrow). E: Section in EC of mice vaccinated by tumor cell vaccine and IFN $\alpha-2 b$ represents great necrotic areas contain of reminants and some pyknotic nuclei $(\uparrow)$. 

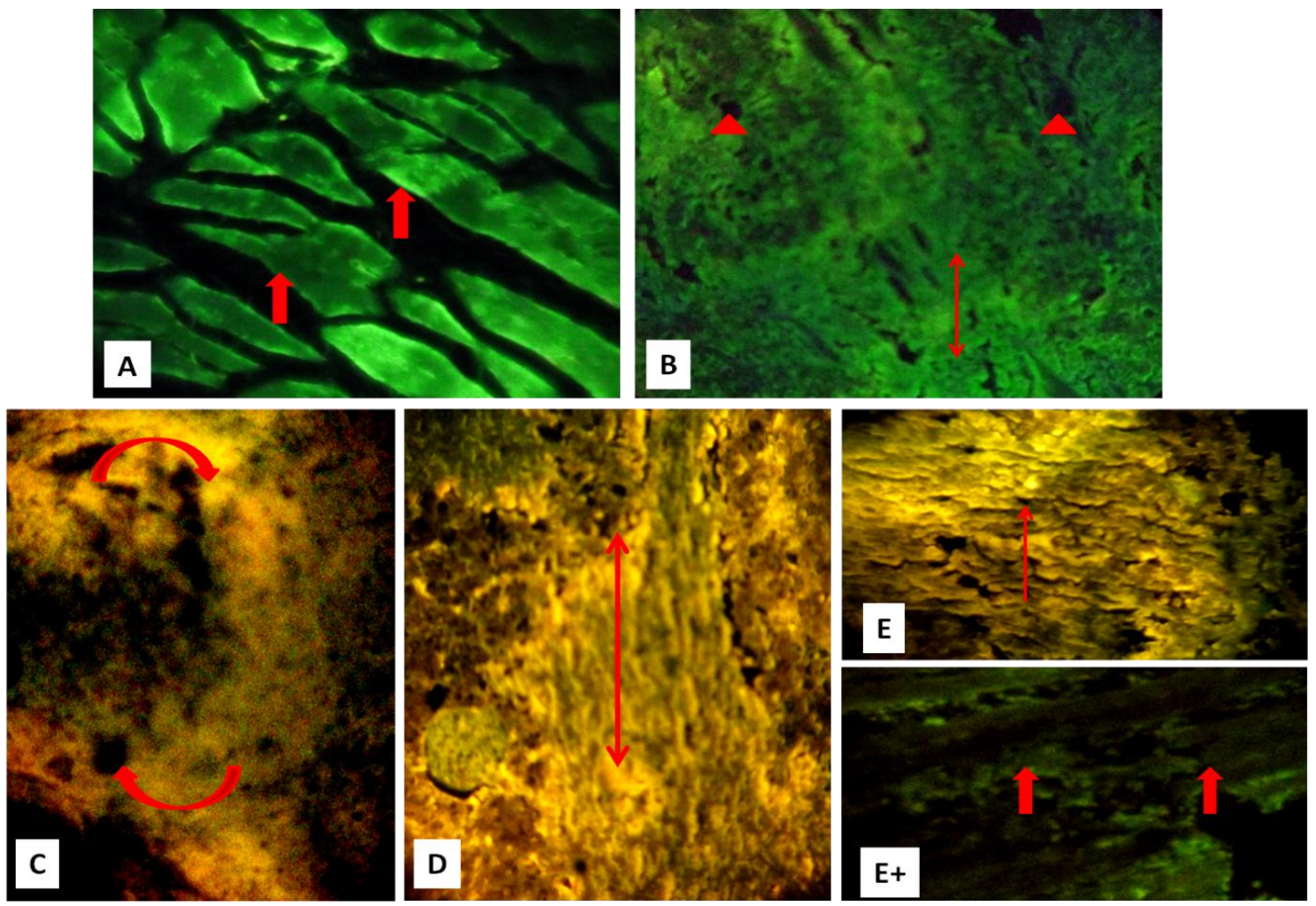

Fig. (4): Fluorescent images of sections in Ehrlich carcinoma stained by Acridine orange / propidium iodide stain. A: Normal muscle represents vital tissue regions stained in green (red blocked arrows). B: Control Ehrlich carcinoma represents vital green regions $(\uparrow)$ and some vacuolated areas $(\mathbf{\Delta})$.C: Section in EC of mice treated by tumor cell vaccine showed necrotic regions had bright orange (red curved arrow). D: Section in EC of mice treated by IFN $\alpha-2 b$ shows extensive bright orange areas of necrotic EC cells contain nuclear debris $(\uparrow)$. E\&E+: Section in EC of mice vaccinated by tumor cell and IFN $\alpha-2 b$ represents great areas showed necrotic regions had late bright orange apoptotic cells and necrotic cells had orange color $(\uparrow)$. Vital green muscle tissue was also observed (red blocked arrows). (X 250) 